Research Article

\title{
Investigating Efficiency of Vector-Valued Intensity Measures in Seismic Demand Assessment of Concrete Dams
}

\author{
Mohammad Alembagheri $(\mathbb{D}$ \\ Department of Civil and Environmental Engineering, Tarbiat Modares University, Tehran, Iran \\ Correspondence should be addressed to Mohammad Alembagheri; alembagheri@modares.ac.ir
}

Received 26 August 2017; Accepted 12 November 2017; Published 23 January 2018

Academic Editor: Fabrizio Mollaioli

Copyright (C) 2018 Mohammad Alembagheri. This is an open access article distributed under the Creative Commons Attribution License, which permits unrestricted use, distribution, and reproduction in any medium, provided the original work is properly cited.

The efficiency of vector-valued intensity measures for predicting the seismic demand in gravity dams is investigated. The Folsom gravity dam-reservoir coupled system is selected and numerically analyzed under a set of two-hundred actual ground motions. First, the well-defined scalar IMs are separately investigated, and then they are coupled to form two-parameter vector IMs. After that, IMs consisting of spectral acceleration at the first-mode natural period of the dam-reservoir system along with a measure of the spectral shape (the ratio of spectral acceleration at a second period to the first-mode spectral acceleration value) are considered. It is attempted to determine the optimal second period by categorizing the spectral acceleration at the first-mode period of vibration. The efficiency of the proposed vector IMs is compared with scalar ones considering various structural responses as EDPs. Finally, the probabilistic seismic behavior of the dam is investigated by calculating its fragility curves employing scalar and vector IMs considering the effect of zero response values.

\section{Introduction}

In the approach of performance-based earthquake engineering $(\mathrm{PBEE})$, the demand on a structure under a given earthquake should be properly estimated [1]. To do this, the intensity of earthquake ground motion is measured by an intensity measure (IM), and the resulted structural response demanded under the earthquake is evaluated using engineering demand parameter (EDP). Then, the probability that earthquake will cause a prescribed level of demand in the structure is computed as a function of the defined IM. These probabilistic predictions of EDPs as a function of IMs can be obtained by statistical analysis of the results of nonlinear dynamic analyses under a set of earthquake ground motions [2-6]. The robustness of the predictions is highly dependent on the selected IMs. Ground motion hazard models can be then combined with IM-EDP relations to compute the seismic reliability of structures [2].

Traditional IMs often include single-valued (scalar) parameters such as peak ground motion values or spectral responses, but it has been shown that vector-valued IMs consisting of multiple parameters of earthquake intensity may lead to better estimation [7-10]. A vector IM would contain more information about the ground motion than a scalar IM, and it has been shown that it is more effective in predicting the response of building frames and bridges [11-17]. Probabilistic seismic assessment of concrete dams using single-valued IMs has been well performed [18-21], but such study employing vector-valued IMs is very scarce.

When a single-valued IM is used, the mean annual rate of exceeding an EDP level such as edp and $\eta_{\mathrm{EDP}}(\mathrm{edp})$ can be computed as

$$
\eta_{\mathrm{EDP}}(\mathrm{edp})=\int_{\mathrm{im}} P[\mathrm{EDP}>\mathrm{edp} \mid \mathrm{IM}=\mathrm{im}] \cdot\left|d \eta_{\mathrm{IM}}(\mathrm{im})\right| .
$$

In this equation, $\eta_{\mathrm{IM}}(\mathrm{im})$ is the mean annual rate of exceeding the IM level im, which is obtained using probabilistic seismic hazard analysis (PSHA) $[22,23] . P[$ EDP > edp|IM $=\mathrm{im}$ ] is the probability of exceeding a specified EDP level of edp, conditioned on the IM level of im; this conditional probability distribution, called fragility, is employed in estimating the efficiency of the selected IMs [2]. $\eta_{\mathrm{EDP}}(\mathrm{edp})$ is the direct measure of the seismic performance and reliability of a structure because it relates to the probability of experiencing the event EDP $>$ edp within the future lifetime of the structure [4]. 
The estimation of (1) can be potentially improved by increasing the number of parameters in the IM. In this way, a more complete description of the properties of ground motions can be obtained [24, 25]. For example, if an EDP is potentially dependent on two ground motion parameters, $\mathrm{IM}_{1}$ and $\mathrm{IM}_{2}$, then the annual rate of exceeding a specified EDP value of edp can be computed using the following modified version of the total probability theorem of (1):

$$
\begin{gathered}
\eta_{\mathrm{EDP}}(\mathrm{edp})=\int_{\mathrm{im}_{1} \int_{\mathrm{im}_{2}}} P\left[\mathrm{EDP}>\operatorname{edp} \mid \mathrm{IM}_{1}=\mathrm{im}_{1}, \mathrm{IM}_{2}=\mathrm{im}_{2}\right] \\
\cdot\left|d \eta_{\mathrm{IM}_{1}, \mathrm{IM}_{2}}\left(\mathrm{im}_{1}, \mathrm{im}_{2}\right)\right|,
\end{gathered}
$$$$
\mathrm{d} \eta_{\mathrm{IM}_{1}, \mathrm{IM}_{2}}\left(\mathrm{im}_{1}, \mathrm{im}_{2}\right)=g_{\mathrm{IM}_{2}=\mathrm{im}_{2} \mid \mathrm{IM}_{1}=\mathrm{im}_{1}} \cdot \operatorname{dim}{ }_{2} \cdot \mathrm{d} \eta_{\mathrm{IM}_{1}}\left(\mathrm{im}_{1}\right),
$$

where $d \eta_{\mathrm{IM} 1, \mathrm{IM} 2}\left(\mathrm{im}_{1}, \mathrm{im}_{2}\right)$ is the joint mean annual frequency of the $\mathrm{IM}_{1}$ and $\mathrm{IM}_{2}$ values, $g_{\mathrm{IM} 2=\mathrm{im} 2 \mid \mathrm{IM} 1=\mathrm{im} 1}$ denotes the conditional probability density function of $\mathrm{IM}_{2}$ given $\mathrm{IM}_{1}, \operatorname{dim}_{2}$ is a small increment in $\mathrm{IM}_{2}$ value, and $d \eta_{\mathrm{IM} 1}\left(\mathrm{im}_{1}\right)$ is the annual rate of $\mathrm{IM}_{1}$ exceeding $\mathrm{im}_{1}$ at the site being considered [4]. The terms $g_{\mathrm{IM} 2=\mathrm{im} 2 \mid \mathrm{IM} 1=\mathrm{im} 1}$ and $d \eta_{\mathrm{IM} 1}\left(\mathrm{im}_{1}\right)$ can be obtained through vector PSHA, or in some cases, with standard PSHA and disaggregation $[9,26]$.

In this paper, the application of vector-valued intensity measures for predicting the seismic demand in gravity dams is examined. For this purpose, Folsom gravity dam is selected as case study and numerically modeled along with its full reservoir using the finite element method in an Eulerian-Lagrangian approach. A set of proper earthquake records including two-hundred actual ground motions are employed. First, different well-established scalar IMs are separately investigated, and then they are coupled to form two-parameter vector IMs. Also, IMs consisting of two parameters of spectral acceleration at the first-mode natural period of the dam-reservoir system along with a measure of spectral shape (the ratio of spectral acceleration at a second period to the first-mode spectral acceleration value) are investigated. It is attempted to determine the optimal second period by categorizing the spectral acceleration at the firstmode period of vibration. The efficiency of the proposed vector IMs is compared with that of the scalar ones considering various structural responses as EDPs. Finally, the seismic performance of the dam is probabilistically investigated by calculating its fragility curves employing scalar and vector IMs to determine whether the various estimates of structural response are equivalent.

\section{Single-and Vector-Valued Intensity Measures}

There are potential approaches to estimate the conditional distribution of EDPs for the given scalar and vector IMs [27], but in the present study, the cloud method is briefly described and employed. This method is based on regression on response data from unscaled ground motions. Considering single-valued (scalar) IMs that contain only a single parameter, the nonlinear dynamic analysis of a structure is performed using a set of unscaled ground motion records. The IM values of the selected records and the associated EDP values obtained from nonlinear dynamic analysis are usually plotted either on an arithmetic or logarithmic scale. This cloud of data is then regressed to compute the conditional mean and standard deviation of EDP given IM [2]. Scatter data points have usually linear trend in the logarithmic scale which implies their power relation in the arithmetic scale:

$$
\lambda_{\mathrm{EDP} \mid \mathrm{IM}}=\alpha_{1}(\mathrm{IM})^{\alpha_{2}},
$$

where $\lambda_{\mathrm{EDP} \mid \mathrm{IM}}$ is the mean value of EDP given IM, and $\alpha_{1}$ and $\alpha_{2}$ are constant coefficients. The IM-EDP relation is called seismic demand model. Taking logarithm on both sides of (4) results in

$$
\ln \left(\lambda_{\mathrm{EDP} \mid \mathrm{IM}}\right)=\ln \alpha_{1}+\alpha_{2} \ln (\mathrm{IM}) .
$$

Two regression coefficients, $\ln \alpha_{1}$ and $\alpha_{2}$, can be estimated using linear least-squares regression [28]. However, the accuracy of the results depends on the validity of implicit assumptions of the linear least-squares method [7]. The prediction error for record $j$, which is called the regression residual, is computed as

$$
\varepsilon_{j}=\ln \left(\mathrm{EDP}_{j} \mid \mathrm{IM}\right)-\ln \left(\lambda_{\mathrm{EDP}_{j} \mid \mathrm{IM}}\right),
$$

where $\mathrm{EDP}_{j}$ is the exact value of EDP under record $j$. These residuals are assumed to be mutually independent; they by definition have a mean of zero. If they are assumed to be normally distributed with constant variance for entire IM range (this condition is termed homoscedasticity [7]), then their standard deviation can be estimated as

$$
s_{\mathrm{EDP} \mid \mathrm{IM}}=\sqrt{\frac{\sum_{i=1}^{N}\left[\ln \left(\mathrm{EDP}_{i} \mid \mathrm{IM}\right)-\ln \left(\lambda_{\mathrm{EDP}_{i} \mid \mathrm{IM}}\right)\right]^{2}}{N-1}},
$$

where $N$ is the number of records. The estimated $s_{\mathrm{EDP} \mid \mathrm{IM}}$ is denoted as dispersion of EDP given IM. In this paper, adopted scalar IMs are strong motion duration $T_{D}$, peak ground motion parameters (PGA, PGV, and PGD), and 5\% damping spectral responses $S_{a}\left(T_{1}\right), S_{a}\left(T_{2}\right), S_{v}\left(T_{1}\right)$, and $S_{d}\left(T_{1}\right)$, where $T_{1}$ and $T_{2}$ are the first- and second-mode natural period of the dam-reservoir system.

The vector-valued IMs can increase the estimation efficiency. Considering additional IM terms results in further explanation of a ground motion's effect on a structure so that the remaining unexplained statistical variability in EDP will be reduced [7]. This means that fewer nonlinear dynamic analyses will be needed to characterize the relationship between the EDP and the IM. Multiple linear regression analysis [28] can be performed on the cloud data with vector-valued IMs. Assuming a vector IM with two elements of $\mathrm{IM}_{1}$ and $\mathrm{IM}_{2}$, a linear functional form, after logarithmic transformation, can be again used to model the relationship between the mean value of EDP, $\lambda_{\mathrm{EDP} \mid \mathrm{IM} 1, \mathrm{IM} 2}$, and IMs

$$
\ln \left(\lambda_{\mathrm{EDP} \mid \mathrm{IM}_{1}, \mathrm{IM}_{2}}\right)=\ln \alpha_{1}+\alpha_{2} \ln \left(\mathrm{IM}_{1}\right)+\alpha_{3} \ln \left(\mathrm{IM}_{2}\right),
$$

where $\ln \alpha_{1}, \alpha_{2}$, and $\alpha_{3}$ are estimated coefficients obtained using multiple linear regression. The dispersion of EDP values given $\mathrm{IM}_{1}$ and $\mathrm{IM}_{2}, s_{\mathrm{EDP} \mid \mathrm{IM} 1, \mathrm{IM} 2}$, can be then computed as 
$s_{\mathrm{EDP}_{\mid \mathrm{IM}}, \mathrm{IM}_{2}}=\sqrt{\frac{\sum_{i=1}^{N}\left[\ln \left(\mathrm{EDP}_{i} \mid \mathrm{IM}_{1}, \mathrm{IM}_{2}\right)-\ln \left(\lambda_{\left.\left.\mathrm{EDP}_{i} \mid \mathrm{IM}_{1}, \mathrm{IM}_{2}\right)\right]^{2}}\right.\right.}{N-1} .}$

This method can be easily generalized to accommodate more IM parameters by simply adding additional terms to (8). Although there are some challenges with this method such as potentially high correlation between adopted IMs, more extrapolations, and interaction between IM parameters, the estimates of mean and standard deviation are obtained using low number of analyses as compared to other estimation methods. So, this method has been extensively used for several investigations using vector-valued IMs $[24,29,30]$.

In this study, the size of the vector IMs is limited to two parameters containing all possible dual combinations of the adopted scalar IMs. Also, a specific class of candidates is considered as potential vector IMs containing $S_{a}\left(T_{1}\right)$, which will be verified as an effective predictor of structural response for gravity dams, and a predictor $\Psi_{1, n}=S_{a}\left(T_{n}\right) / S_{a}\left(T_{1}\right)$, which is a measure of spectral shape [2]. These parameters define two points on the acceleration spectrum of a ground motion. $T_{n}$ is a second arbitrary period that can vary such that the value that optimally predicts the dam response is determined. The spectral shape predictor $\Psi_{1, n}$ has been shown to be a useful predictor of structural response [31,32]. It should be noted that the same procedure is easily applicable to vectors of a larger size.

Choosing an optimal IM is based on the criteria of efficiency (small variability of EDP for records with the same IM value), sufficiency, and ease of calculation. The adopted scalar and vector IMs are easy to calculate and familiar to many engineers. The sufficiency of the scalar IMs has been investigated elsewhere [33], and the addition of a second element will not render the IM insufficient $[2,7]$. So in this study, the efficiency criterion is the main point. The efficiency is measured by dispersion coefficients computed from (7) and (9). The accuracy of the regression estimate using both scalar and vector IMs is increased by decreasing the standard deviation of the regression residuals or dispersion [7]. It has been shown that vectorvalued IMs can achieve significant gains in efficiency for building- and bridge-type structures [2, 25, 29, 34]; hence, this approach can reduce the number of dynamic analyses that must be performed to assess the structure's performance for a specific accuracy level.

\section{Probabilistic Seismic Assessment}

When a scalar IM is used, if $\ln (\mathrm{EDP} \mid \mathrm{IM})$ is assumed to have a Gaussian distribution, then the estimated conditional probability of exceeding an EDP level edp given IM = im is computed as [2]

$$
P[\mathrm{EDP}>\operatorname{edp} \mid \mathrm{IM}=\mathrm{im}]=1-\Phi\left(\frac{\operatorname{lnedp}-\ln \left(\lambda_{\mathrm{EDP} \mid \mathrm{IM}}\right)}{s_{\mathrm{EDP} \mid \mathrm{IM}}}\right),
$$

where $\Phi(\cdot)$ is the cumulative distribution function of the standard Gaussian distribution. By plotting $P[E D P>$ edp|IM $=\mathrm{im}$ ] against various IM levels, the fragility curve is obtained. This prediction requires that the relationship between EDP and IM to be linear with constant variance after logarithmic transformation. This restriction may be appropriate only over a limited range of IM levels, but its advantage is reduced computational cost of the estimation and closed-form analytical solution for (1) and (2) [35-38].

Until now, it was assumed that EDP given IM has a lognormal distribution. However, it should be noted that the structural response of the dam may be zero under some earthquake ground motions. It is the case, for example, for the tensile damage imposed to the dam body. These zero quantities then have infinite logarithm, and they alter the estimation. So, to properly address this issue in computing the conditional probabilities, first it is required to account the probability of zero response (ZR) parameters, through the following equation, in terms of the considered IM in the main prediction equation [16]:

$$
P[\mathrm{ZR} \mid \mathrm{IM}=\mathrm{im}]=1-\Phi\left(\mathrm{im}, \lambda_{\mathrm{ZR} \mid \mathrm{IM}}, s_{\mathrm{ZR} \mid \mathrm{IM}}\right),
$$

where $\lambda_{\mathrm{ZR} \mid \mathrm{IM}}$ and $s_{\mathrm{ZR} \mid \mathrm{IM}}$ are the mean and standard deviation of IM values corresponding to zero response parameters, respectively. Now, the modified conditional probability is given by combining the two probabilities [2]:

$$
\begin{aligned}
P[\mathrm{EDP}>\operatorname{edp} \mid \mathrm{IM}=\mathrm{im}] & =(1-P[\mathrm{ZR} \mid \mathrm{IM}=\mathrm{im}]) \\
& \cdot\left(1-\Phi\left(\frac{\operatorname{lnedp}-\ln \left(\widehat{\lambda}_{\mathrm{EDP} \mid \mathrm{IM}}\right)}{\widehat{s}_{\mathrm{EDP} \mid \mathrm{IM}}}\right)\right),
\end{aligned}
$$

where $\hat{\lambda}$ and $\widehat{s}$ are sample mean and standard deviation, respectively, of the nonzero response values. The same procedure can be employed for computing fragility curves when the vector IMs are used. Assuming that $\ln \left(\mathrm{EDP} \mid \mathrm{IM}_{1}\right.$, $\mathrm{IM}_{2}$ ) is normally distributed with the standard deviation of $s_{\mathrm{EDP} \mid \mathrm{IM} 1, \mathrm{IM} 2}$, the probability of exceeding the EDP level edp given $\mathrm{IM}=<\mathrm{IM}_{1}, \mathrm{IM}_{2}>$ and nonzero response (NZR) values, is

$$
\begin{aligned}
P[\mathrm{EDP} & \left.>\operatorname{edp} \mid \mathrm{IM}_{1}=\mathrm{im}_{1}, \mathrm{IM}_{2}=\mathrm{im}_{2}, \mathrm{NZR}\right] \\
& =1-\Phi\left(\frac{\operatorname{lnedp}-\ln \left(\lambda_{\mathrm{EDP} \mid \mathrm{IM}_{1}, \mathrm{IM}_{2}}\right)}{s_{\mathrm{EDP} \mid \mathrm{IM}_{1}, \mathrm{IM}_{2}}}\right) .
\end{aligned}
$$

This equation is similar to (10) used in the scalar case. The effect of zero response values may be taken into account same as that described in (11) and (12).

\section{Dam Model and Ground Motion Selection}

The nonoverflow monolith of Folsom gravity dam is chosen for the purpose of analysis. It is a well-shaped gravity dam that has been extensively studied in literature [39-42]. The 


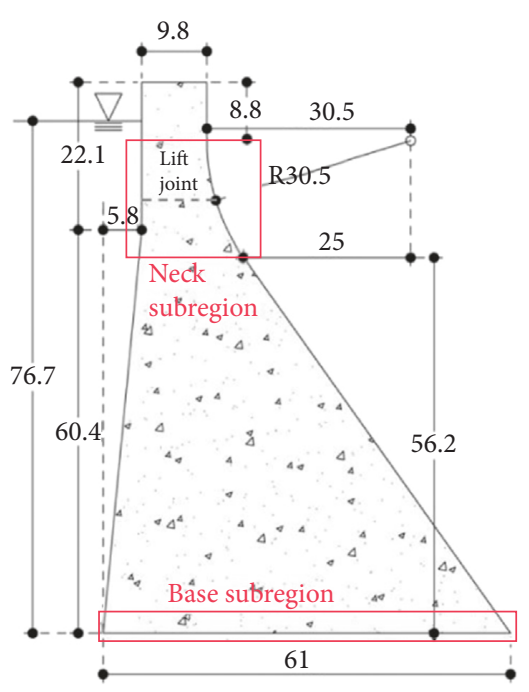

(a)

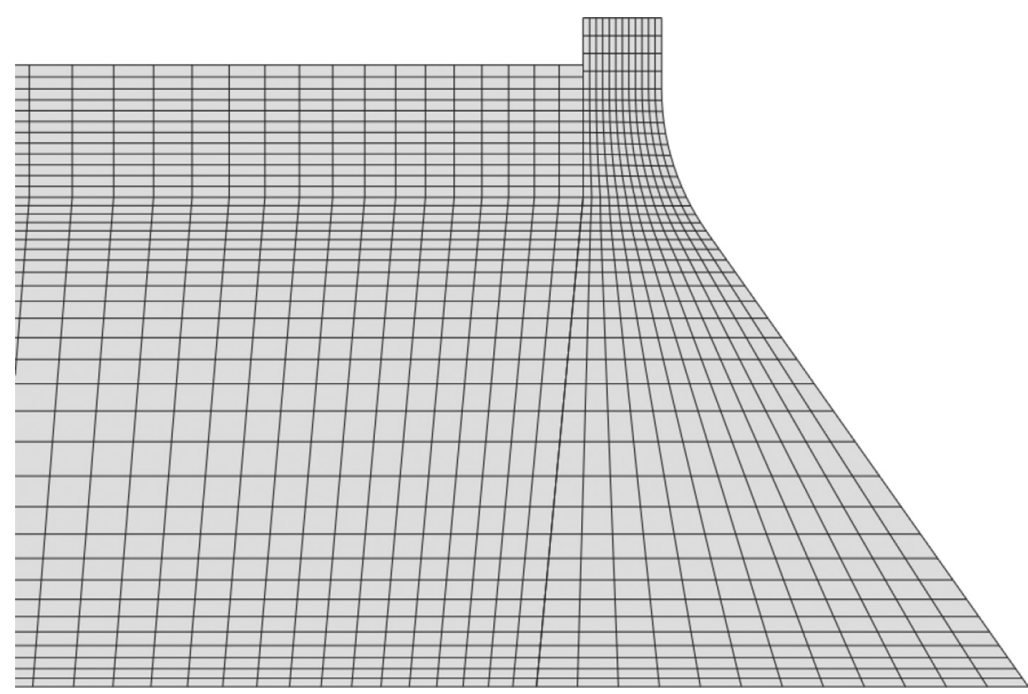

(b)

Figure 1: (a) The tallest nonoverflow monolith of Folsom gravity dam, the shown dimensions are in meters. (b) The finite-element discretized mesh of the dam and part of the reservoir.

dam is two-dimensionally modeled in a plane-stress manner along with its full reservoir utilizing the finite element method, as shown in Figure 1; the water-structure dynamic interaction is considered employing Eulerian-Lagrangian formulation. The foundation is assumed rigid. The reservoir length is considered to be five times the dam height, and nonreflecting boundary condition is assigned to its truncated far-end [43]. The mesh has been sufficiently refined such that it properly detects the nonlinear response of the dam body. The nonlinear behavior of mass concrete in tension is modeled using the plastic-damage method as described in [44]. The stiffness degradation of mass concrete in tension, beyond its tensile strength $\left(f_{t}\right)$, is determined defining a tensile damage parameter $\left(d_{t}\right)$ which is assumed to be function of the plastic strains. This parameter can vary from zero, representing the undamaged material, to one, which represents the total loss of strength. The considered constitutive behavior of mass concrete in this study is illustrated in Figure 2. The behavior of mass concrete in compression is assumed linear. The material properties are tabulated in Table 1. They are assumed the same during static and dynamic analysis.

The EDPs are the outcome of the nonlinear seismic finite element analysis of the dam-reservoir system. The adopted EDPs are crest maximum relative displacement $\left(\Delta_{c}\right)$, in $\mathrm{cm}$, and two dimensionless local damage indices, DI, from (14), which are separately calculated for the base and neck areas; they are the most susceptible areas to cracking [39]. These areas are shown in Figure 1(a):

$$
\mathrm{DI}_{i}=\frac{\int_{i} d_{t} \cdot d A_{e \mid i}}{\int_{i} d A_{e \mid i}}, \quad i=\text { base or neck area, }
$$

where $d A_{e \mid i}$ is the differential area of element $e$ in area $i$. The summation is done on the entire area $i$ and shows the amount of damage that the dam may locally experience. $\mathrm{DI}_{i}$ varies between zero, showing no element cracks, and one

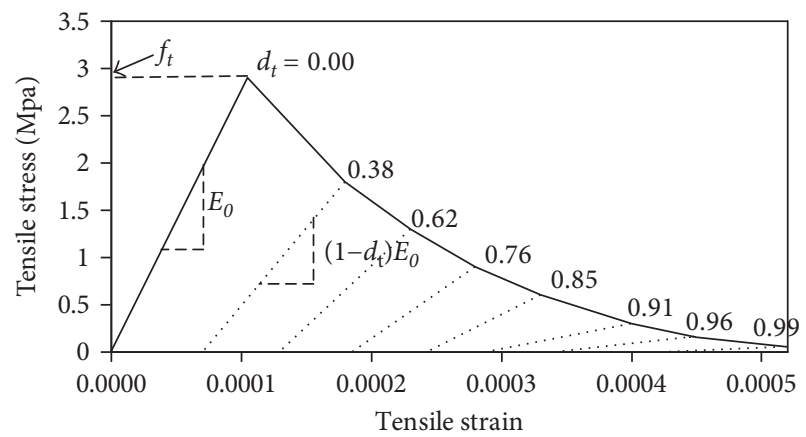

FIGURE 2: Stress-strain constitutive relation of dam concrete in uniaxial tension [21].

TABLe 1: Material properties of dam concrete and reservoir water.

\begin{tabular}{lcc}
\hline Material & Property & Value \\
\hline \multirow{4}{*}{ Concrete } & Density $\left(\mathrm{kg} / \mathrm{m}^{3}\right)$ & 2400 \\
& Initial elastic modulus $(\mathrm{GPa})$ & 27.58 \\
& Poisson's ratio & 0.2 \\
\multirow{2}{*}{ Water } & Tensile strength $(\mathrm{MPa})$ & 2.9 \\
& Density $\left(\mathrm{kg} / \mathrm{m}^{3}\right)$ & 1000 \\
\hline
\end{tabular}

indicating that all elements fully crack. Another EDP is defined as the energy dissipated through cracking damage process, $E_{D}$, in $\mathrm{MJ}$, which can be considered as a global measure of damage imposed to the dam body.

Two-hundred historical earthquake ground motions are used in the probabilistic analysis to investigate the effects of earthquake characteristics like intensity, frequency content, and strong motion duration on the gravity dam's structural demands. This high number of records would lead to statistically meaningful response results. All of the records are extracted from the PEER strong motion database [45], 


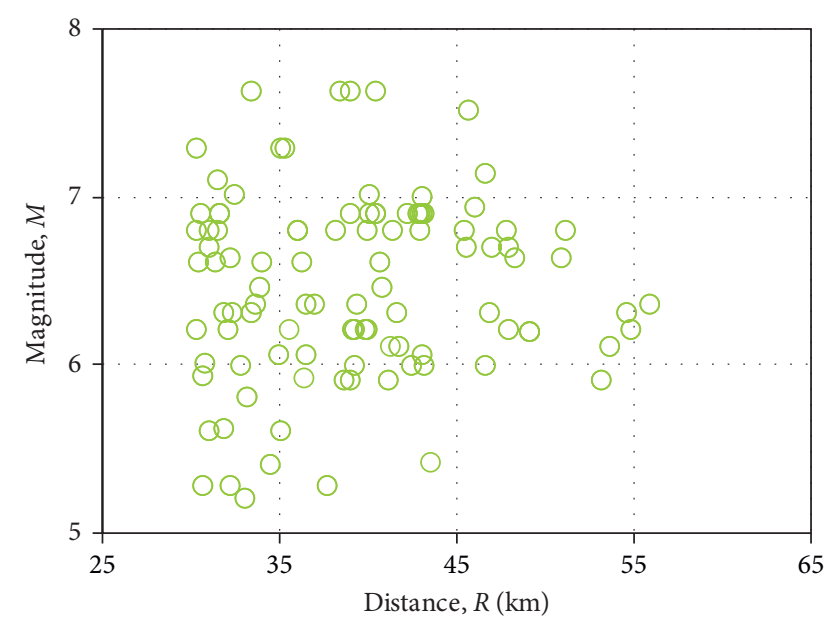

FIGURE 3: Distribution of the 200 earthquake ground motions in the $M-R$ plane.

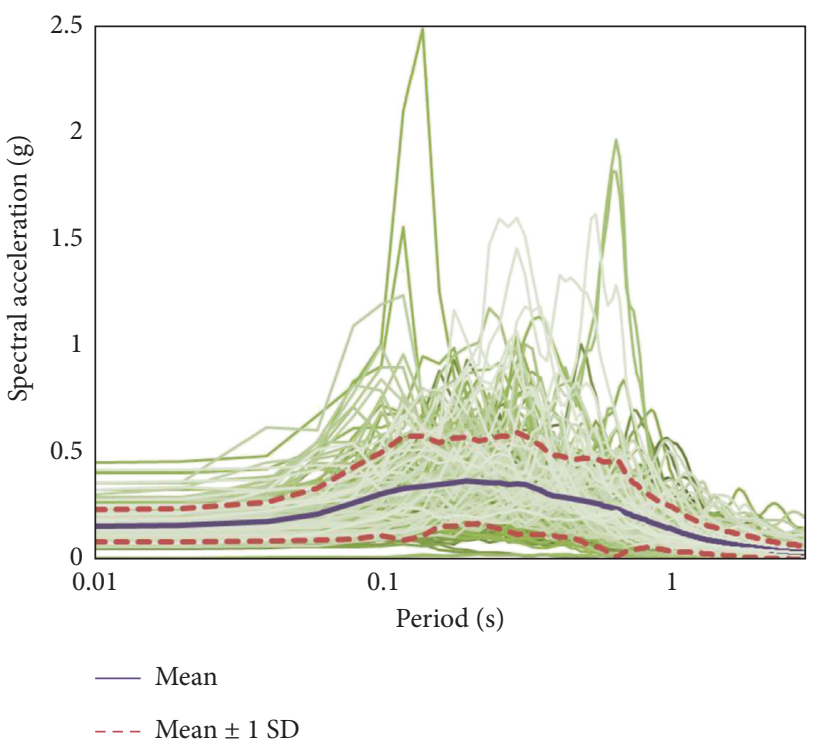

Figure 4: Acceleration response spectra of the selected earthquake records.

from the earthquake events with the magnitude $(M)$ range of 5 to 8 . Their distances $(R)$ vary between 30 and $60 \mathrm{~km}$; they are recorded on ground with shear wave velocity more than $360 \mathrm{~m} / \mathrm{s}$ which corresponds to rock or very dense soil class of the USGS soil classification [46]. Gravity dams are normally constructed on such grounds. It has been attempted to avoid directivity effects by choosing records without near-fault and pulse-like characteristics. The distribution of the selected ground motions in M-R plane, shown in Figure 3, indicates no statistical relationship between $M$ and $R$. The acceleration response spectra of all 200 selected earthquake records are depicted in Figure 4.

The dam is loaded statistically under the self-weight and the hydrostatic pressure of the full reservoir before dynamic analysis under the selected earthquake ground motions. The Rayleigh damping is employed that produces $5 \%$ critical damping in the first and third vibration modes of the coupled dam-reservoir system.

\section{Prediction of Dam Responses}

In this section, the prediction potential of the adopted IMs for various EDPs is investigated by assessing the dispersion of IM-EDP pairs considering both scalar and vector IMs; the optimal pair with the lowest dispersion is identified.

5.1. Single-Valued IMs. Examples of regression of $\Delta_{c}$ as EDP are separately illustrated in Figure 5 versus $S_{a}\left(T_{1}\right)$ and PGD as scalar IMs in logarithmic scale. Also shown are the normal distribution fits of the cloud data points in the logarithmic scale. As it is observed, selecting scalar IM as $S_{a}\left(T_{1}\right)$ and PGD results in small and large residual standard deviation, respectively, which shows high and low efficiency. So, the trend in the cloud data can be clearly estimated more accurately using the $S_{a}\left(T_{1}\right)$ as a single-valued IM. The calculated dispersion and goodness of fitting $\left(R^{2}\right)$ values for all possible IM-EDP pairs are tabulated in Table 2. From this table, the lowest variability belongs to $\Delta_{c}$ when it is coupled with various scalar IMs; $\mathrm{DI}_{\text {neck }}$ shows almost the highest variability. The strong motion duration, $T_{D}$, produces the largest dispersion values which shows its inefficiency in estimating the seismic demand of the dam structure, but $S_{a}\left(T_{1}\right)$ as IM has the lowest dispersion when it is considered with various EDPs. The highest $R^{2}$ values also belong to the pairs with $S_{a}\left(T_{1}\right)$ as scalar IM.

It was concluded that $S_{a}\left(T_{1}\right)$ is the best predictor among the other scalar IMs. For the 200 selected earthquake records, $S_{a}\left(T_{1}\right)$ varies between $0.017 \mathrm{~g}$ and $1.110 \mathrm{~g}$. In this wide range, the dam may behave completely linear to highly nonlinear. To better assess its performance, the earthquake records are divided into four groups with the following $S_{a}\left(T_{1}\right)$ ranges: (1) $0.0-0.2 \mathrm{~g}$, (2) $0.2-0.4 \mathrm{~g}$, (3) $0.4-0.6 \mathrm{~g}$, and (4) more than $0.6 \mathrm{~g}$. It is noteworthy that, in the first range, that is, $0.0<S_{a}\left(T_{1}\right)<0.2 \mathrm{~g}$, the dam responds completely linear or very slightly nonlinear without any cracking in the neck area. For $S_{a}\left(T_{1}\right)$ between 0.2 and $0.4 \mathrm{~g}$, the dam behaves moderately nonlinear, some records cause cracking in the neck area. In the third range, the nonlinear behavior extends, but when $S_{a}\left(T_{1}\right)$ is more than $0.6 \mathrm{~g}$, that is, in the fourth range, the dam shows severe nonlinear response such that all records cause neck cracking. The dispersion values are recomputed considering these new ranges of $S_{a}\left(T_{1}\right)$, the results are shown in Table 3. The number of records that causes nonzero EDP values in each $S_{a}\left(T_{1}\right)$ group is also reported in this table. The last column of the table shows the dispersion values considering all of the earthquake records. For $\Delta_{c}$ as EDP, this grouping reduces the dispersion to very small values when the dam behaves linearly to moderately nonlinear, that is, in the first and second group. But it increases the dispersion when the dam responds highly nonlinear in the third and fourth group. However, the opposite trend is observed for the other EDPs that are directly related to the nonlinear response. In these cases, the dispersion decreases for higher $S_{a}\left(T_{1}\right)$ levels where the dam behaves completely nonlinear. For examples, the dispersion 


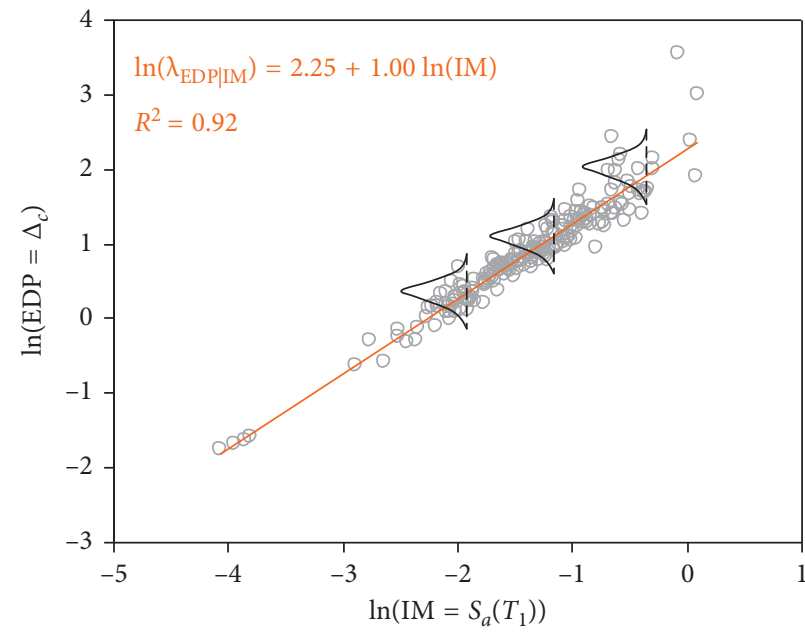

(a)

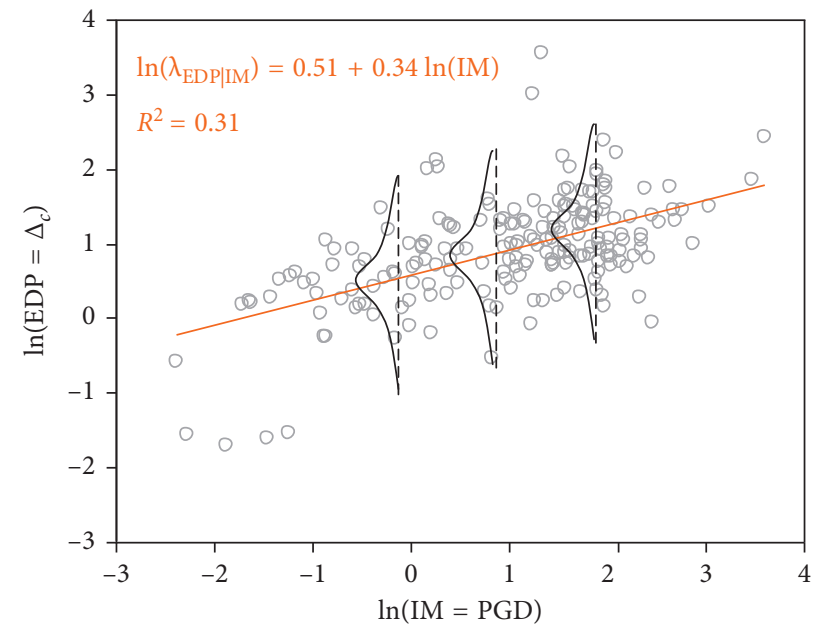

(b)

FIGURE 5: Illustrations of estimating the conditional mean value from linear regression of $\ln \left(\Delta_{c}\right)$ from cloud data: $\left(\right.$ a) $\mathrm{IM}=S_{a}\left(T_{1}\right)$ and (b) $\mathrm{IM}=$ PGD. The normal distribution of the data points obtained from the mean and standard deviation of the regression is also shown.

TABLE 2: Dispersion of EDP|IM considering single-valued IMs. The numbers in parentheses are the $R^{2}$ values of the corresponding linear regressions.

\begin{tabular}{|c|c|c|c|c|c|}
\hline \multirow{2}{*}{ Intensity measure } & \multirow{2}{*}{ Unit } & \multicolumn{4}{|c|}{ Engineering demand parameter } \\
\hline & & $\Delta_{c}$ & $\mathrm{DI}_{\text {base }}$ & $\mathrm{DI}_{\text {neck }}$ & $E_{D}$ \\
\hline$T_{D}$ & sec & $0.709(0.02)$ & $0.878(0.01)$ & $1.341(0.00)$ & $1.245(0.01)$ \\
\hline PGA & $\mathrm{g}$ & $0.477(0.55)$ & $0.739(0.30)$ & $1.128(0.29)$ & $0.933(0.37)$ \\
\hline PGV & $\mathrm{cm} / \mathrm{s}$ & $0.467(0.57)$ & $0.685(0.40)$ & $1.214(0.18)$ & $0.948(0.43)$ \\
\hline PGD & $\mathrm{cm}$ & $0.594(0.31)$ & $0.793(0.19)$ & $1.319(0.03)$ & $1.122(0.19)$ \\
\hline$S_{a}\left(T_{1}\right)$ & $\mathrm{g}$ & $0.202(0.92)$ & $0.377(0.82)$ & $0.899(0.55)$ & $0.453(0.87)$ \\
\hline$S_{a}\left(T_{2}\right)$ & g & $0.300(0.82)$ & $0.592(0.55)$ & $1.054(0.38)$ & $0.776(0.61)$ \\
\hline$S_{v}\left(T_{1}\right)$ & $\mathrm{cm} / \mathrm{s}$ & $0.595(0.31)$ & $0.817(0.14)$ & $0.797(0.65)$ & $1.141(0.17)$ \\
\hline$S_{d}\left(T_{1}\right)$ & $\mathrm{cm}$ & $0.592(0.31)$ & $0.805(0.17)$ & $0.901(0.55)$ & $1.126(0.19)$ \\
\hline
\end{tabular}

TABLE 3: Dispersion of EDP|IM for IM as various ranges of $S_{a}\left(T_{1}\right)$. The numbers in parentheses show the number of earthquake records that cause nonzero response values in each group.

\begin{tabular}{lccccc}
\hline EDP & & \multicolumn{3}{c}{ Variation range of $S_{a}\left(T_{1}\right)$} & $0.6-1.11 \mathrm{~g}$ \\
\hline$\Delta_{c}$ & $0.0-0.2 \mathrm{~g}$ & $0.2-0.4 \mathrm{~g}$ & $0.4-0.6 \mathrm{~g}$ & $0.409(17)$ & $0.202(200)$ \\
$\mathrm{DI}_{\text {base }}$ & $0.133(68)$ & $0.138(84)$ & $0.279(31)$ & $0.165(17)$ & $0.377(184)$ \\
$\mathrm{DI}_{\text {neck }}$ & $0.376(52)$ & $0.271(84)$ & $0.201(31)$ & $0.610(17)$ & $0.899(48)$ \\
$E_{D}$ & $-(0)$ & $0.603(10)$ & $0.756(21)$ & $0.353(17)$ & $0.453(184)$ \\
\hline
\end{tabular}

is decreased about $56 \%, 32 \%$, and $22 \%$ for $\mathrm{DI}_{\text {base }}, \mathrm{DI}_{\text {neck }}$, and $E_{D}$, respectively, in the fourth range as compared with the entire range. So, it is concluded that considering the earthquake records which are actually in (or are scaled to) the specific levels of $S_{a}\left(T_{1}\right)$ could result in lower dispersion and higher prediction potential for the gravity dam structural behavior.

5.2. Vector-Valued IMs. To investigate the vector IMs, first suppose that EDP is $\Delta_{c}$. The multiple linear regression of
$\Delta_{c}$ in terms of vector $\mathrm{IM}=<S_{a}\left(T_{1}\right), \mathrm{IM}_{2}>$, in logarithmic scale, is illustratively shown in Figure 6 separately for $\mathrm{IM}_{2}=\mathrm{PGA}$ and PGD. The multiple linear regression for IM $=<S_{a}\left(T_{1}\right)$, PGA $>$ would result in $\ln \left(\lambda_{\Delta_{c} \mid S_{a}\left(T_{1}\right), \text { PGA }}\right)=$ $2.38+0.939 \ln \left(S_{a}\left(T_{1}\right)\right)+0.111 \ln (\mathrm{PGA})$ with $R^{2}=0.92$ and $s_{\Delta_{c} \mid S_{a}\left(T_{1}\right), \mathrm{PGA}}=0.198$. Comparing this result with the simple linear regression of $\ln \left(\lambda_{\Delta_{c} \mid S_{a}\left(T_{1}\right)}\right)$ shown in Figure $5(\mathrm{a})$, it is observed that both regression formulas are approximately the same, with PGA contributing to low correlation coefficient of 0.111 which results in only $2 \%$ reduction in the dispersion. Choosing $\mathrm{IM}=<S_{a}\left(T_{1}\right), \mathrm{PGD}>$ leads to 


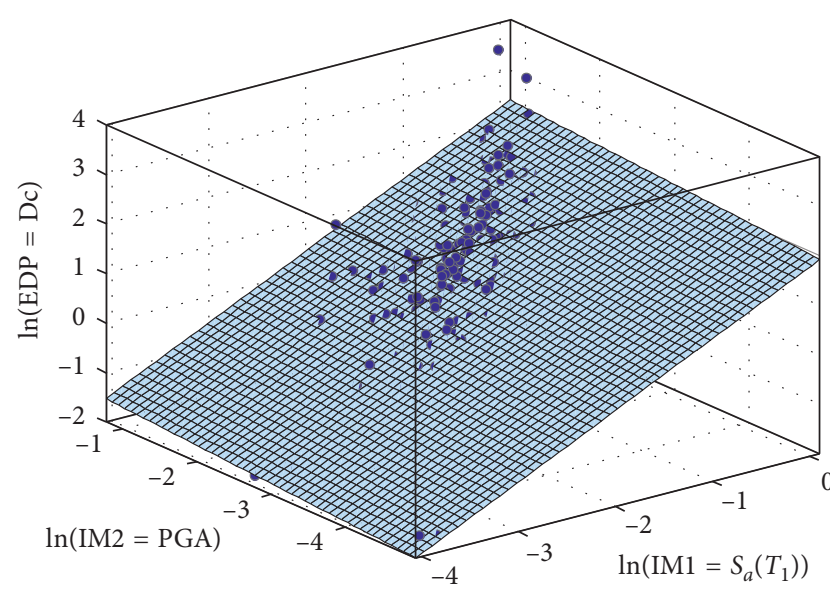

(a)

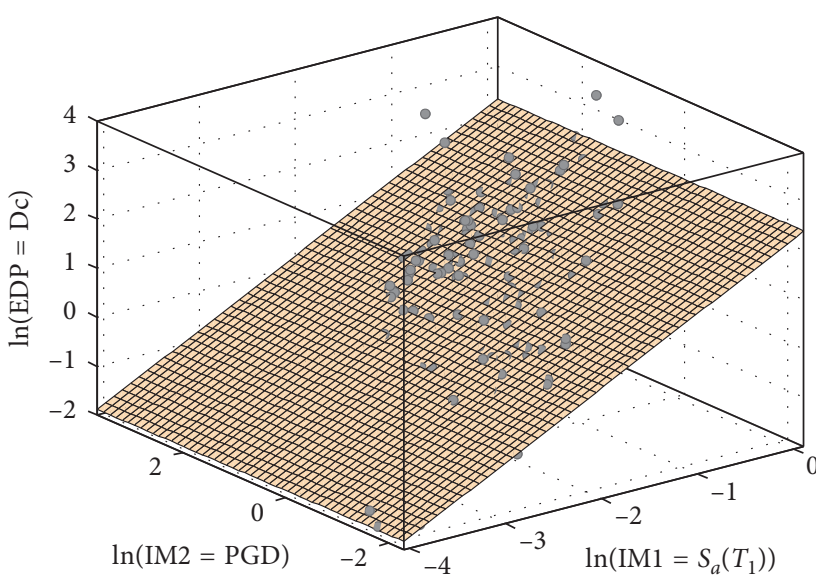

(b)

FIGURE 6: Estimates of mean of $\ln \left(\Delta_{c}\right)$ as a function of vector $\mathrm{IM}=<\mathrm{IM}_{1}=S_{a}\left(T_{1}\right), \mathrm{IM}_{2}>$ using multiple linear regression on the 3D cloud data: (a) $\mathrm{IM}_{2}=$ PGA and (b) $\mathrm{IM}_{2}=$ PGD.

TABLE 4: Dispersion of EDP|IM $\mathrm{IM}_{1}, \mathrm{IM}_{2}$. The upper and lower triangles show the dispersion values for the EDP as $\Delta_{c}$ and $E_{D}$, respectively.

\begin{tabular}{lcccccccc}
\hline \multirow{2}{\mathrm{IM}_{1}}{} & \multicolumn{8}{c}{$\mathrm{IM}_{2}$} \\
& PGA & PGV & PGD & $S_{a}\left(T_{1}\right)$ & $S_{a}\left(T_{2}\right)$ & $S_{v}\left(T_{1}\right)$ & $S_{d}\left(T_{1}\right)$ & $T_{D}$ \\
\hline PGA & - & 0.414 & 0.443 & 0.198 & 0.297 & 0.451 & 0.445 & 0.463 \\
PGV & 0.881 & - & 0.457 & 0.202 & 0.295 & 0.434 & 0.437 & 0.463 \\
PGD & 0.936 & 0.939 & - & 0.202 & 0.300 & 0.520 & 0.522 & 0.573 \\
$S_{a}\left(T_{1}\right)$ & 0.455 & 0.452 & 0.452 & - & 0.201 & 0.202 & 0.202 & 0.203 \\
$S_{a}\left(T_{2}\right)$ & 0.773 & 0.738 & 0.766 & 0.441 & - & 0.297 & 0.296 & 0.301 \\
$S_{v}\left(T_{1}\right)$ & 0.969 & 0.912 & 1.044 & 0.454 & 0.776 & - & 0.594 & 0.592 \\
$S_{d}\left(T_{1}\right)$ & 0.955 & 0.909 & 1.036 & 0.454 & 0.771 & 1.099 & - & 0.590 \\
$T_{D}$ & 0.980 & 0.944 & 1.102 & 0.450 & 0.779 & 1.140 & 1.126 & - \\
\hline
\end{tabular}

regression of $\ln \left(\lambda_{\Delta_{c} \mid S_{a}\left(T_{1}\right), \mathrm{PGD}}\right)=2.27+1.014 \ln \left(S_{a}\left(T_{1}\right)\right)-0.009$ $\ln (\mathrm{PGD})$ with $R^{2}=0.92$ and $s_{\Delta_{c} \mid S_{a}\left(T_{1}\right), \mathrm{PGA}}=0.202$. From Table 2, PGD has low-efficient relation with $\Delta_{c}$ as $\operatorname{EDP}\left(s_{\Delta_{\mathrm{f}} \mathrm{PGD}}=0.594\right)$, so it is observed that when one term of the vector IM has very lower correlation with EDP with respect to another term, it essentially contributes with very low coefficient in the multiple linear regression formula, and the resulted dispersion and $R^{2}$ values will not be substantially affected. Considering IM $=\langle$ PGA, PGD $>$ would result in $\ln \left(\lambda_{\Delta_{\mid} \text {PGA,PGD }}\right)=2.29+0.814 \ln (\mathrm{PGA})+$ $0.173 \ln (\mathrm{PGD})\left(R^{2}=0.62, s_{\Delta_{c} \mathrm{PGA}, \mathrm{PGD}}=0.443\right)$, so the weight of PGD is increased as the correlation of the first term, now PGA, with the selected EDP reduces.

The dispersion values for the vector IMs consisting of all dual combinations of the scalar IMs are reported in Table 4 coupled with $\mathrm{EDP}=\Delta_{c}$ and $E_{D}$, and in Table 5 coupled with $\mathrm{EDP}=\mathrm{DI}_{\text {base }}$ and $\mathrm{DI}_{\text {neck. }}$. The above explanations can be again observed in these tables. Therefore, it is concluded that the relative efficiency of the elements of a vector IM is a key point in their effects on the regression analysis. From Tables 4 and 5, it is observed that direct combination of scalar IMs to produce vector IMs can partly decrease the dispersion and increase the efficiency of the
TABLE 5: Dispersion of EDP|IM $\mathrm{IM}_{1}, \mathrm{IM}_{2}$. The upper and lower triangles show the dispersion values for EDP as $\mathrm{DI}_{\text {base }}$ and $\mathrm{DI}_{\text {neck, }}$, respectively.

\begin{tabular}{lcccccccc}
\hline \multirow{2}{\mathrm{IM}_{1}}{} & \multicolumn{8}{c}{$\mathrm{IM}_{2}$} \\
& PGA & PGV & PGD & $S_{a}\left(T_{1}\right)$ & $S_{a}\left(T_{2}\right)$ & $S_{v}\left(T_{1}\right)$ & $S_{d}\left(T_{1}\right)$ & $T_{D}$ \\
\hline PGA & - & 0.657 & 0.696 & 0.376 & 0.593 & 0.724 & 0.714 & 0.729 \\
PGV & 1.127 & - & 0.682 & 0.377 & 0.565 & 0.666 & 0.663 & 0.684 \\
PGD & 1.145 & 1.207 & - & 0.376 & 0.582 & 0.748 & 0.741 & 0.782 \\
$S_{a}\left(T_{1}\right)$ & 0.749 & 0.887 & 0.913 & - & 0.362 & 0.377 & 0.378 & 0.374 \\
$S_{a}\left(T_{2}\right)$ & 0.956 & 1.040 & 1.072 & 0.907 & - & 0.592 & 0.589 & 0.593 \\
$S_{v}\left(T_{1}\right)$ & 0.688 & 0.773 & 0.810 & 0.807 & 0.804 & - & 0.774 & 0.815 \\
$S_{d}\left(T_{1}\right)$ & 0.750 & 0.889 & 0.915 & 0.760 & 0.909 & 0.807 & - & 0.804 \\
$T_{D}$ & 1.146 & 1.211 & 1.330 & 0.912 & 1.054 & 0.805 & 0.914 & - \\
\hline
\end{tabular}

prediction model as compared to that obtained from more efficient component of the vector IM. The lowest dispersion belongs to vector $\mathrm{IM}=<S_{a}\left(T_{1}\right)$, PGA $>$, coupled with $\Delta_{c}$, with the value of 0.198 that shows about $2 \%$ reduction with respect to scalar $\mathrm{IM}=S_{a}\left(T_{1}\right)$.

In the next step, the specific class of the vector IMs composed of $S_{a}\left(T_{1}\right)$, which was verified as an efficient predictor of dam responses, and $\Psi_{1, n}=S_{a}\left(T_{n}\right) / S_{a}\left(T_{1}\right)$, where $T_{n}$ is a second arbitrary period, is considered. The regression results are normalized to compute the fractional reduction in dispersion relative to that one obtained from the scalar $\mathrm{IM}=S_{a}\left(T_{1}\right)$. If the fractional reduction is zero, then no efficiency is gained by including the given $\Psi_{1, n}$. The optimal $T_{n}$ that has the largest fractional reduction among all possible $T_{n}$ values is the best choice that reduces the randomness [7]. A plot of the fractional reduction in dispersion is shown in Figure 7 for various EDPs. Also shown is the range of first $\left(T_{1}\right)$ to fifth $\left(T_{5}\right)$ natural periods of the dam-reservoir system. From this figure, the optimal $T_{n}$ value is different for various EDPs, but it is located near or between $T_{1}$ and $T_{5}$ range. The maximum fractional reduction in dispersion for $\Delta_{c}$ is as low as about $6 \%$, while the reduction of $18 \%$ can be obtained for $\mathrm{DI}_{\text {neck. }}$ Because the gravity dams are essentially first-mode 


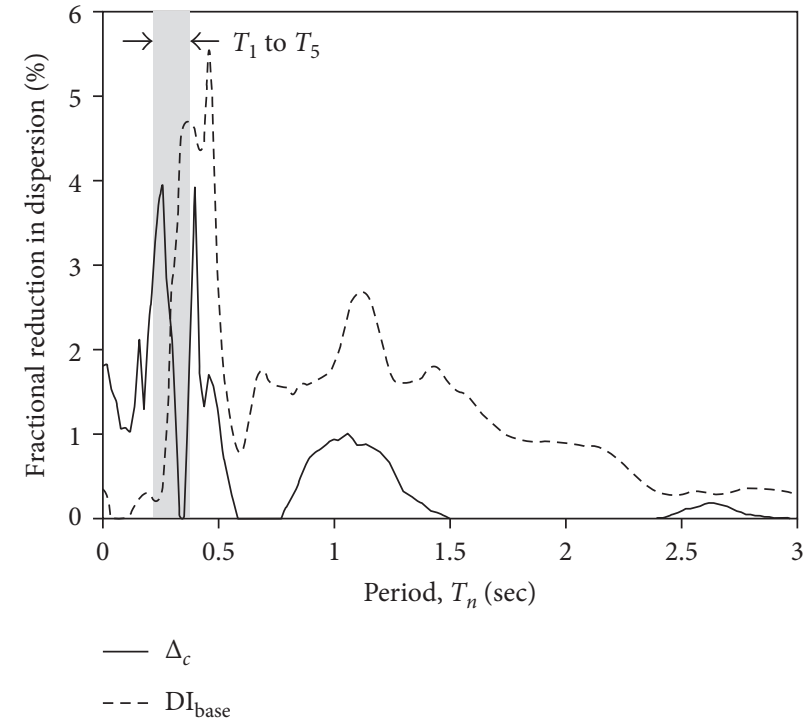

(a)

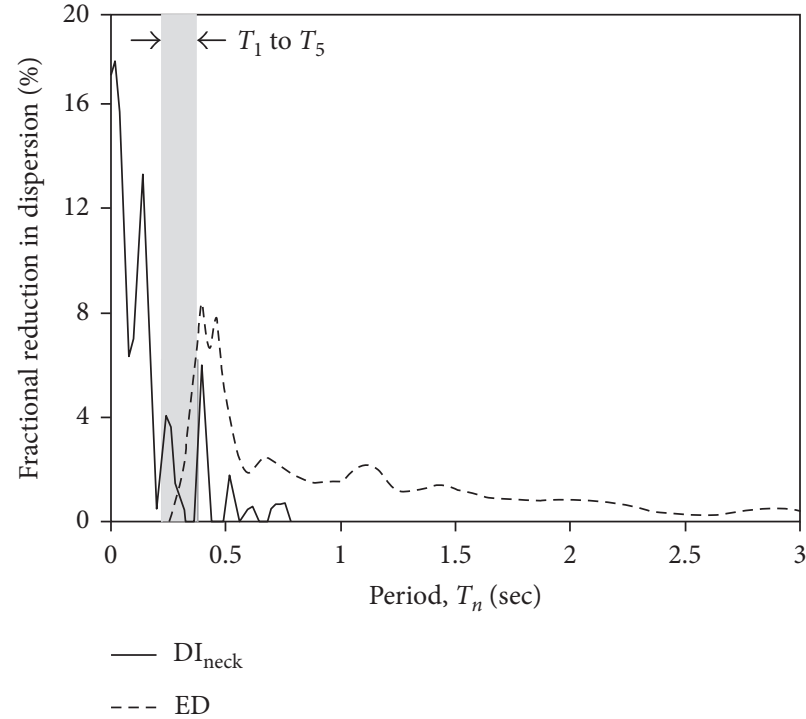

(b)

Figure 7: Fractional reduction in dispersion in terms of $T_{n}$ for EDP as (a) $\Delta_{c}$ and DI $\mathrm{base}_{\text {and }}$ (b) $E_{D}$ and DI $\mathrm{I}_{\text {neck. }}$. The first element of the vector IM is $S_{a}\left(T_{1}\right)$, and the second element is $\Psi_{1, n}=S_{a}\left(T_{n}\right) / S_{a}\left(T_{1}\right)$.

dominated structures [39], the dispersion reduction is low with respect to those obtained for building frames [7]. The standard errors of estimation can be compared as [7]

$$
\frac{s_{\text {scalar }}}{\sqrt{N_{\text {scalar }}}}=\frac{s_{\text {vector }}}{\sqrt{N_{\text {vector }}}},
$$

where $N_{\text {scalar }}$ and $N_{\text {vector }}$ are the number of records used in the analysis taking into account the scalar and vector IMs, respectively. So, by $18 \%$ reduction in dispersion $\left(s_{\text {vector }}=\right.$ $0.82 s_{\text {scalar }}$ ), it is obtained that $N_{\text {vector }}=0.67 N_{\text {scalar. }}$. It means that, by adopting more efficient vector-valued IMs, the number of required records can be potentially reduced about 33\%; however, they still maintain the same accuracy in the estimate of the mean response of the dam-reservoir system. This can lead to high reduction in computational cost.

To investigate the effects of $S_{a}\left(T_{1}\right)$ level on the obtained results, the same grouping of $S_{a}\left(T_{1}\right)$, as it was used for the scalar IM, is employed, and the efficiency of including the $\Psi_{1, n}$ as the second element of vector IM is separately assessed for each group. As a reminder, the groups of $S_{a}\left(T_{1}\right)$ levels are (1) 0-0.2 g, (2) 0.2-0.4 g, (3) 0.4-0.6 g, and (4) more than $0.6 \mathrm{~g}$. The dispersion values are computed considering the vector IM $=\left\langle S_{a}\left(T_{1}\right), \Psi_{1, n}>\right.$ for each group; the fractional reductions in dispersion are plotted for various EDPs in Figure 8. Also shown is $T_{1}-T_{5}$ range of the dam-reservoir system. As it is observed, by limiting the computation in particular ranges of $S_{a}\left(T_{1}\right)$, much higher reduction in dispersion may be obtained. For $0.0<S_{a}\left(T_{1}\right)<0.2 \mathrm{~g}$, since the dam stays linear or very slightly nonlinear, the reduction of dispersion is considerable just for $\operatorname{EDP}=\Delta_{c}$, where the optimal $T_{n}$ is $0.22 \mathrm{sec}$, which is the fifth-mode period of the dam-reservoir system, with approximately $15 \%$ reduction. This vector IM is comparable to the modal analysis method of estimating linear response which uses the spectral accelerations at the first and fifth modes of the system. If $0.2 \mathrm{~g}<S_{a}\left(T_{1}\right)<0.4 \mathrm{~g}$, then the most reduction occurs for

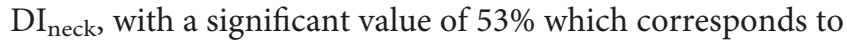
reduction of number of records by a scale of 4.5 (through (15)); however, the number of records in this range of $S_{a}\left(T_{1}\right)$ which causes nonzero $\mathrm{DI}_{\text {neck }}$ is just 10 records (Table 3 ). So, the conclusion may not be very reliable. For the other EDPs, the reduction is at most below $7 \%$.

Within the third range, that is, $0.4 \mathrm{~g}<S_{a}\left(T_{1}\right)<0.6 \mathrm{~g}$, the optimal $T_{n}$ is located at $0.4 \mathrm{sec}$, a little more than $T_{1}$, for all EDPs. In this range, most of the records cause some level of nonlinear behavior in the dam body. The highest reduction belongs to $\mathrm{DI}_{\text {neck }}$ with the value of $39 \%$ which leads to $63 \%$ reduction in the number of records to obtain the same estimation accuracy when the vector-valued IM is used. For the other EDPs, if $T_{n}$ varies between $0.4 \mathrm{sec}$ and $0.52 \mathrm{sec}$, the reduction in dispersion is at least $40 \%$ of the reduction seen at the optimal $T_{n}$. When $0.6<S_{a}\left(T_{1}\right)$, most of the records experience very large levels of nonlinearity, and the optimal $T_{n}$ is located in a range higher than that was obtained for the third level. The maximum fractional reductions are $48 \%$, $38 \%, 19 \%$, and $15 \%$ for $E_{D}, \mathrm{DI}_{\text {base }}, \Delta_{c}$, and $\mathrm{DI}_{\text {neck }}$, respectively. Also the comparable reduction in dispersion can be obtained at a larger range of $T_{n}$ as compared with other $S_{a}\left(T_{1}\right)$ groups. The dependence of $T_{n}$ on the level of nonlinearity has been previously recognized for other structure types $[7,31,32]$. The increase in $T_{n}$ with increasing level of nonlinearity has been explained by the idea of an equivalent linear system in [7].

From the above explanations, it is concluded that if $S_{a}\left(T_{1}\right)$ is low enough that few or no records cause nonlinearity, then the optimal second period $T_{n}$ would be the fifth-mode period of the gravity dam-reservoir coupled system, and if $S_{a}\left(T_{1}\right)$ is large enough that most records cause 


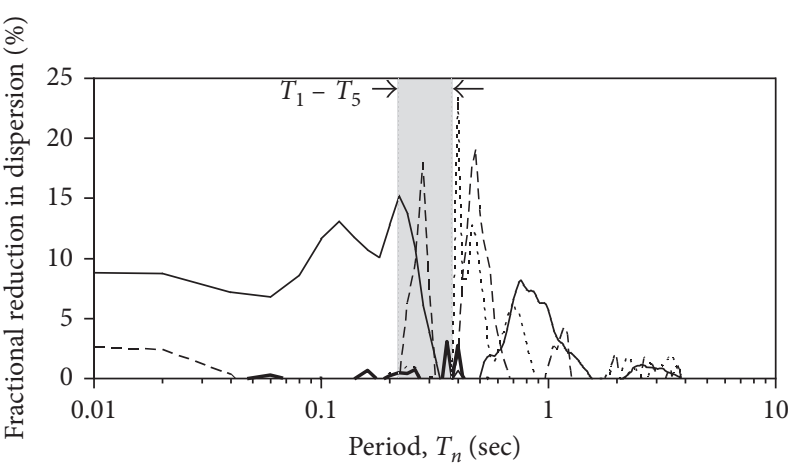

$$
\begin{aligned}
& -0.0<S_{a}\left(T_{1}\right)<0.2 \mathrm{~g} \quad \ldots .0 .4 \mathrm{~g}<S_{a}\left(T_{1}\right)<0.6 \mathrm{~g} \\
& -0.2 \mathrm{~g}<S_{a}\left(T_{1}\right)<0.4 \mathrm{~g} \quad--0.6 \mathrm{~g}<S_{a}\left(T_{1}\right)
\end{aligned}
$$

(a)

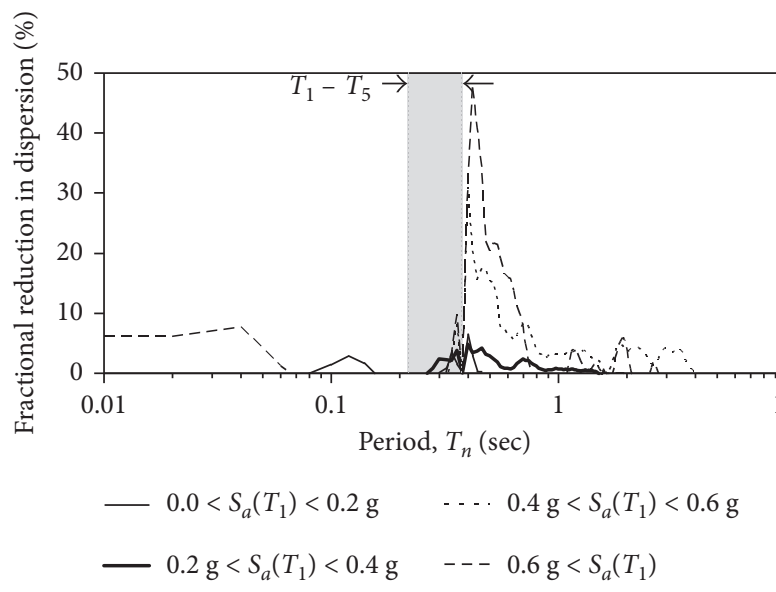

(c)

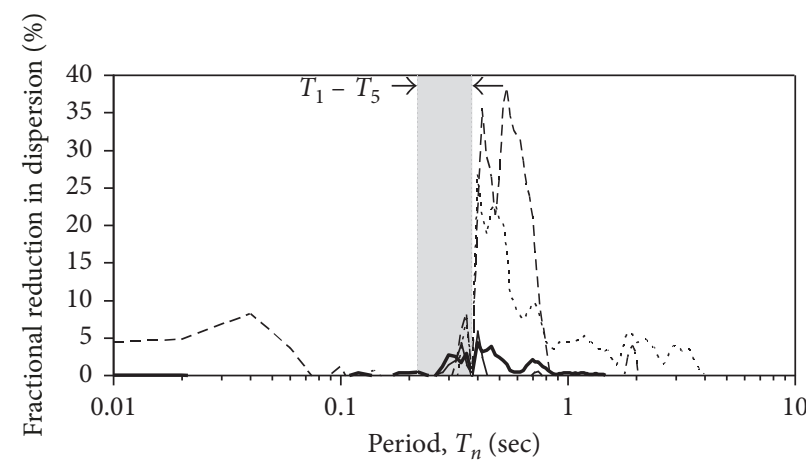

$$
\begin{aligned}
& -0.0<S_{a}\left(T_{1}\right)<0.2 \mathrm{~g} \quad-\cdots 0.4 \mathrm{~g}<S_{a}\left(T_{1}\right)<0.6 \mathrm{~g} \\
& -0.2 \mathrm{~g}<S_{a}\left(T_{1}\right)<0.4 \mathrm{~g} \quad--0.6 \mathrm{~g}<S_{a}\left(T_{1}\right)
\end{aligned}
$$

(b)

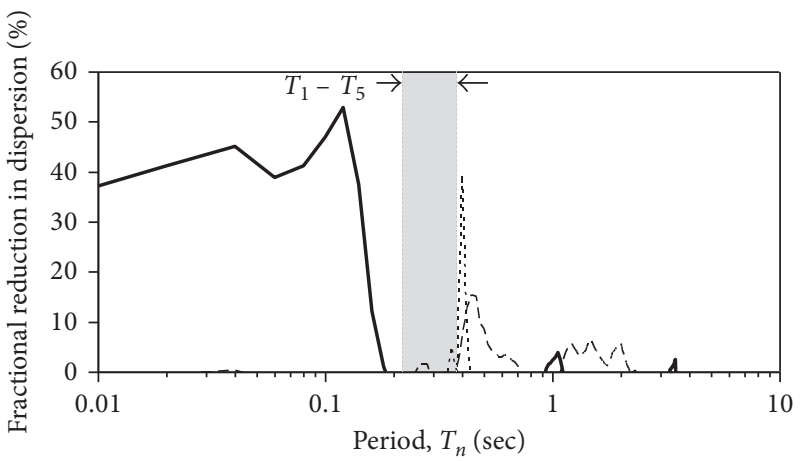

$$
\begin{aligned}
& -0.2 \mathrm{~g}<S_{a}\left(T_{1}\right)<0.4 \mathrm{~g} \quad---0.6 \mathrm{~g}<S_{a}\left(T_{1}\right) \\
& -\ldots 0.4 \mathrm{~g}<S_{a}\left(T_{1}\right)<0.6 \mathrm{~g}
\end{aligned}
$$

(d)

Figure 8: Fractional reduction in dispersion versus $T_{n}$ for different $S_{a}\left(T_{1}\right)$ levels considering $\operatorname{IM}=\left\langle S_{a}\left(T_{1}\right), \Psi_{1, n}>\right.$ : (a) EDP $=\Delta_{c}$, (b) $\mathrm{EDP}=\mathrm{DI}_{\text {base }}$, (c) $\mathrm{EDP}=E_{D}$, and (d) $\mathrm{EDP}=\mathrm{DI}_{\text {neck}}$.

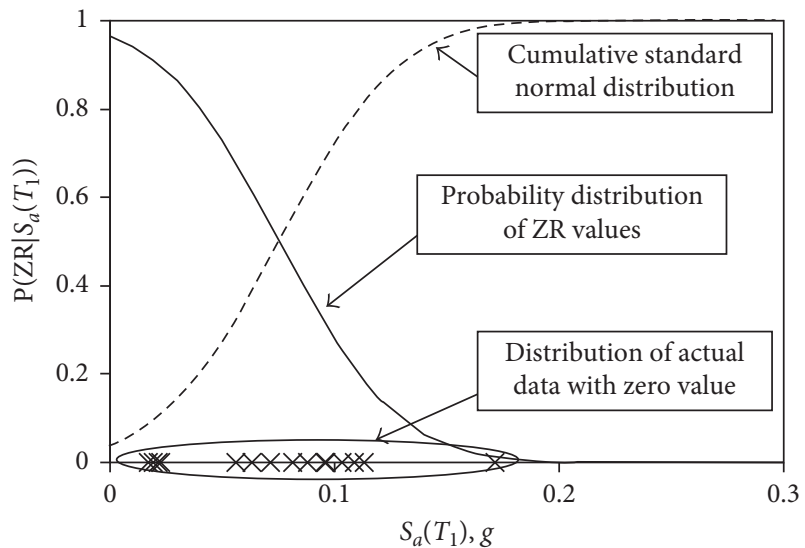

Figure 9: Actual distribution of zero response values for $\mathrm{DI}_{\text {base }}$ in terms of $\mathrm{IM}=S_{a}\left(T_{1}\right)$ along with the fitted cumulative standard normal distribution and the probability distribution of $\mathrm{ZR}$ values.

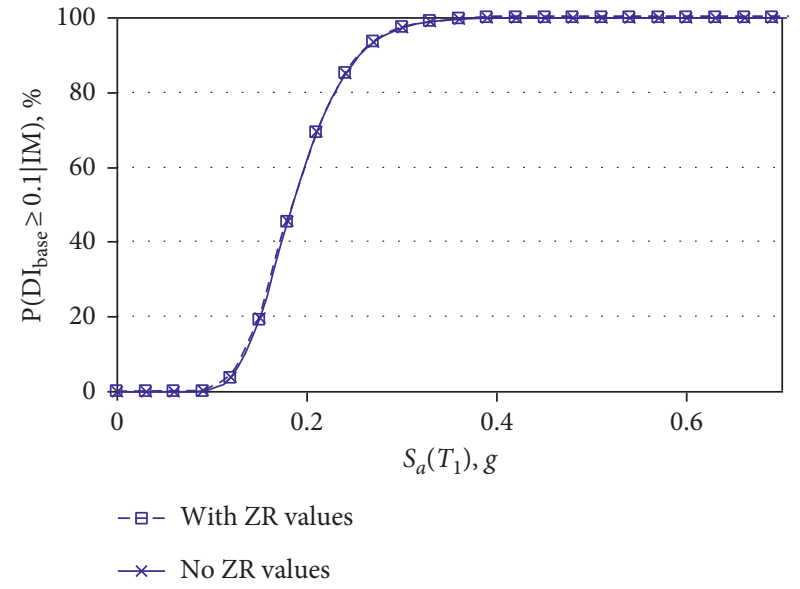

FIGURE 10: Fragility curve of $\mathrm{DI}_{\text {base }} \geq 0.1$ in terms of $S_{a}\left(T_{1}\right)$ with and without the effect of $\mathrm{ZR}$ values. 


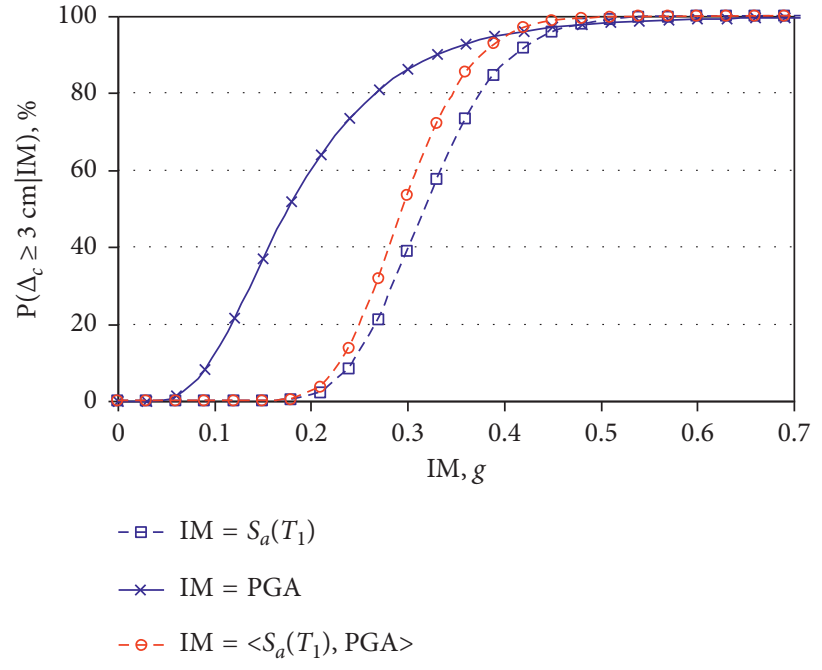

(a)

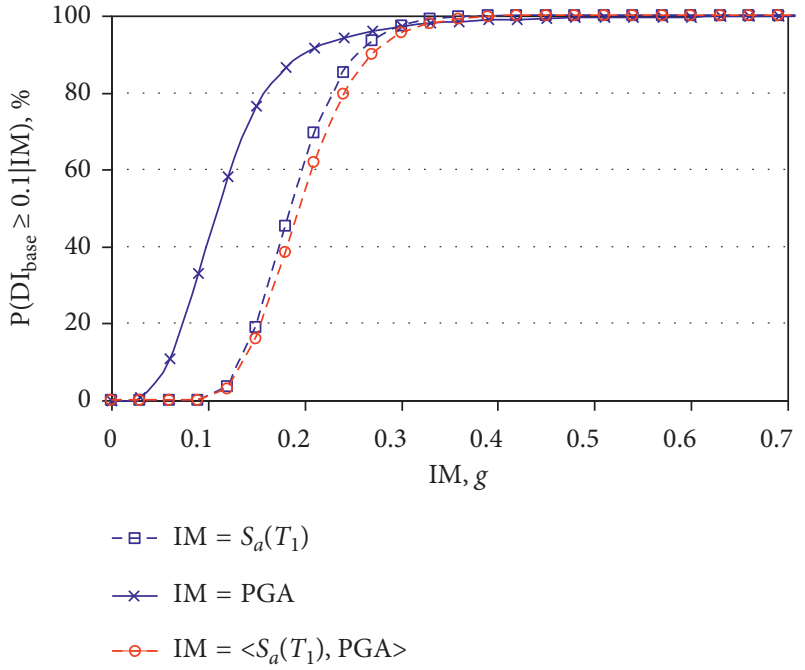

(b)

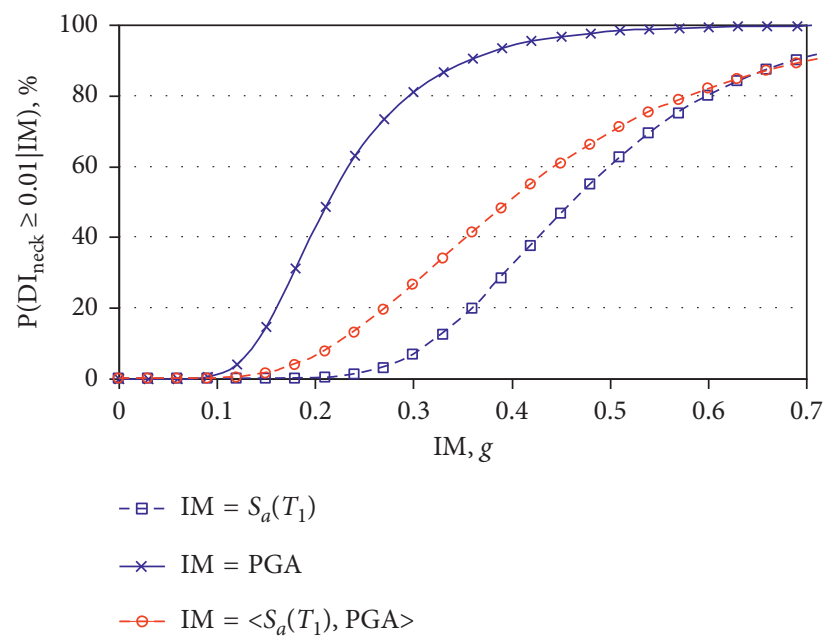

(c)

FIGURE 11: Seismic fragility curves considering the scalar and vector IMs to predict (a) $\Delta_{c} \geq 3 \mathrm{~cm}$, (b) $\mathrm{DI}_{\text {base }} \geq 0.1$, and (c) DI neck $\geq 0.01$.

nonlinear responses, then the optimal $T_{n}$ would be larger than $T_{1}$. Since the optimal second IM is dependent on the level of shaking or $S_{a}\left(T_{1}\right)$ value, using vector-valued IM in a fully probabilistic analysis would be more complicated, as it is required to switch IMs when integrating hazards from low to high levels.

\section{Seismic Fragility Curves}

After investigating the efficiency of IM-EDP pairs considering both single- and vector-valued IMs, the fragility functions can be computed from (12) and (13) incorporating estimates of zero and nonzero response values at various IM levels. The actual distribution of zero response values for $\mathrm{DI}_{\text {base }}$ in terms of $S_{a}\left(T_{1}\right)$ along with the fitted cumulative standard normal distribution and the probability distribution of ZR values obtained from (11) are shown in Figure 9.
The fragility curves of $\mathrm{DI}_{\text {base }} \geq 0.1$, which corresponds to more than $10 \%$ base cracking, in terms of scalar IM $=S_{a}\left(T_{1}\right)$ are shown in Figure 10 with and without considering zero response $(\mathrm{ZR})$ values. It should be noted that 16 records do not cause base cracking at all (Table 3). Because the probability of ZR values becomes actually zero for $S_{a}\left(T_{1}\right)$ $>0.2 \mathrm{~g}$ as observed in Figure 9, the two curves in Figure 10 are very close to each other.

As another illustration, the seismic fragility curves are generated using scalar IMs $=S_{a}\left(T_{1}\right)$ and PGA and vector $\mathrm{IM}=<S_{a}\left(T_{1}\right)$, PGA $>$. They are depicted in Figures 11(a)11 (c) to predict $\Delta_{c} \geq 3 \mathrm{~cm}, \mathrm{DI}_{\text {base }} \geq 0.1$, and $\mathrm{DI}_{\text {neck }} \geq 0.01$, respectively. The considered thresholds are subjective, and their exact definition is beyond the scope of this study; however, they are selected to illustratively compare the fragility curves. These fragility curves are with ZR values. There is not a large difference between the curves of the vector IM and one from scalar IM $=S_{a}\left(T_{1}\right)$, because as it was 
observed, considering PGA as an additional element does not essentially affect the IM-EDP relation. The ultimate goal is calculating the mean annual frequency of exceeding an EDP level from (1) and (2). The reduction in variability is a good criterion to use the vector IMs for accurate calculation. However, this calculation using the vector IMs requires knowledge of vector ground motion hazard which is beyond the scope of this paper. Such hazard analysis is available $[25,47]$ but not yet in widespread use in engineering practice [7].

\section{Conclusions}

Application of vector-valued intensity measures for predicting the seismic demand in gravity dams was studied by numerical analysis of Folsom gravity dam-reservoir coupled system under a set of two-hundred actual ground motions. The efficiency of the defined IMs was examined through dispersion of IM-EDP pairs. Considering different wellestablished scalar IMs showed that the strong motion duration produces very high dispersion values, but $S_{a}\left(T_{1}\right)$ has the lowest dispersion when it is considered with various EDPs. It was found that categorizing $S_{a}\left(T_{1}\right)$ in specific levels could result in lower dispersion and higher accuracy of the prediction model.

Direct combination of the scalar IMs to produce twoparameter vector IMs showed that relative efficiency of the elements of the vector IM is a key point in their effects on the regression analysis. This type of vector IMs partly decrease the dispersion and increase the efficiency of the prediction model as compared to that obtained from more efficient components of the vector IM. Considering a specific class of vector IMs composed of spectral acceleration at the first-mode natural period of the dam-reservoir system along with a measure of spectral shape (the ratio of spectral acceleration at a second period to the first-mode spectral acceleration value), it was found that lower dispersion values with respect to the most-efficient scalar IM, that is, $S_{a}\left(T_{1}\right)$, can be obtained. The optimal second period is different for various EDPs, but it is located near the range of the first to fifth natural period of the system. It was observed that by limiting the computation in particular ranges of $S_{a}\left(T_{1}\right)$, much higher reduction in dispersion may be obtained; however, the optimal second period is dependent on the level of nonlinearity. If $S_{a}\left(T_{1}\right)$ is low enough that few or no records cause nonlinearity, then the optimal second period would be the fifth-mode period of the gravity damreservoir coupled system, and if $S_{a}\left(T_{1}\right)$ is large enough that most records cause nonlinear responses, then the optimal second period would be larger than $T_{1}$. Finally, the probabilistic seismic performance of the dam was investigated by calculating its fragility curves employing scalar and vector IMs incorporating estimates of zero and nonzero response values.

\section{Conflicts of Interest}

The authors declare that they have no conflicts of interest.

\section{References}

[1] C. A. Cornell and H. Krawinkler, "Progress and challenges in seismic performance assessment," PEER Center News, vol. 3, no. 2, pp. 1-3, 2000.

[2] J. W. Baker, "Probabilistic structural response assessment using vector-valued intensity measures," Earthquake Engineering \& Structural Dynamics, vol. 36, no. 13, pp. 1861-1883, 2007.

[3] N. Tondini and B. Stojadinovic, "Probabilistic seismic demand model for curved reinforced concrete bridges," Bulletin of Earthquake Engineering, vol. 10, no. 5, pp. 1455-1479, 2012.

[4] P. Tothong and N. Luco, "Probabilistic seismic demand analysis using advanced ground motion intensity measures," Earthquake Engineering \& Structural Dynamics, vol. 36, no. 13, pp. 1837-1860, 2007.

[5] Y. Tang and J. Zhang, "Probabilistic seismic demand analysis of a slender RC shear wall considering soil-structure interaction effects," Engineering Structures, vol. 33, no. 1, pp. 218-229, 2011.

[6] K. R. Mackie and B. Stojadinovic, "Comparison of incremental dynamic, cloud, and stripe methods for computing probabilistic seismic demand models," in Structures Congress 2005, Metropolis and Beyond, April 2005.

[7] J. W. Baker and C. A. Cornell, "Choice of a vector of ground motion intensity measures for seismic demand hazard analysis," in 13th World Conference on Earthquake Engineering, (No. 3384), Vancouver, BC, Canada, August 2004.

[8] A. A. Theophilou, M. K. Chryssanthopoulos, and A. J. Kappos, "A vector-valued ground motion intensity measure incorporating normalized spectral area," Bulletin of Earthquake Engineering, vol. 15, no. 1, pp. 249-270, 2017.

[9] J. W. Baker and C. A. Cornell, "A vector-valued ground motion intensity measure consisting of spectral acceleration and epsilon," Earthquake Engineering \& Structural Dynamics, vol. 34, no. 10, pp. 1193-1217, 2005.

[10] B. A. Bradley, "The seismic demand hazard and importance of the conditioning intensity measure," Earthquake Engineering \& Structural Dynamics, vol. 41, no. 11, pp. 1417-1437, 2012.

[11] M. Yakhchalian, A. Nicknam, and G. G. Amiri, "Optimal vector-valued intensity measure for seismic collapse assessment of structures," Earthquake Engineering and Engineering Vibration, vol. 14, no. 1, pp. 37-54, 2015.

[12] Z. Li, Y. Li, and N. Li, "Vector-intensity measure based seismic vulnerability analysis of bridge structures," Earthquake Engineering and Engineering Vibration, vol. 13, no. 4, pp. 695-705, 2014.

[13] E. Bojórquez, A. Reyes-Salazar, and S. E. Ruiz, "On the use of vector-valued intensity measure to predict peak and cumulative demands of steel frames under narrow-band motions," Applied Mechanics and Materials, vol. 595, pp. 137-142, 2014.

[14] P. Bazzurro and C. A. Cornell, "Seismic hazard analysis of nonlinear structures. I: methodology," Journal of Structural Engineering, vol. 120, no. 11, pp. 3320-3344, 1994.

[15] G. Wang, "Efficiency of scalar and vector intensity measures for seismic slope displacements," Frontiers of Structural and Civil Engineering, vol. 6, no. 1, pp. 44-52, 2012.

[16] G. Wang and W. Du, "Spatial cross-correlation models for vector intensity measures (PGA, Ia, PGV, and SAs) considering regional site conditions," Bulletin of the Seismological Society of America, vol. 103, no. 6, pp. 3189-3204, 2013.

[17] W. Du and G. Wang, "Fully probabilistic seismic displacement analysis of spatially distributed slopes using spatially 
correlated vector intensity measures," Earthquake Engineering \& Structural Dynamics, vol. 43, no. 5, pp. 661-679, 2014.

[18] M. Alembagheri and M. Ghaemian, "Incremental dynamic analysis of concrete gravity dams including base and lift joints," Earthquake Engineering and Engineering Vibration, vol. 12, no. 1, pp. 119-134, 2013.

[19] A. Lupoi and C. Callari, "Probabilistic seismic assessment of concrete dams," Safety, Reliability and Risk of Structures, Infrastructures and Engineering Systems, pp. 1758-1765, 2010.

[20] M. Alembagheri and M. Seyedkazemi, "Seismic performance sensitivity and uncertainty analysis of gravity dams," Earthquake Engineering \& Structural Dynamics, vol. 44, no. 1, pp. 41-58, 2015.

[21] M. Alembagheri and M. Ghaemian, "Seismic performance evaluation of a jointed arch dam," Structure and Infrastructure Engineering, vol. 12, no. 2, pp. 256-274, 2016.

[22] S. L. Kramer, Geotechnical Earthquake Engineering, Vol. 653, Prentice-Hall, Upper Saddle River, NJ, USA, 1996.

[23] R. K. McGuire, Seismic Hazard and Risk Analysis, Earthquake Engineering Research Institute, Berkeley, CA, USA, 2004.

[24] N. Shome and C. A. Cornell, Probabilistic Seismic Demand Analysis of Nonlinear Structures. RMS-35, Vol. 320, RMS Program, Stanford, CA, USA, 1999, http://www.stanford.edu/ group/rms/.

[25] P. Bazzurro and C. A. Cornell, "Vector-valued probabilistic seismic hazard analysis," in Proceedings of the Seventh U.S. National Conference on Earthquake Engineering, vol. 10, Earthquake Engineering Research Institute, Boston, MA, USA, July 2002.

[26] J. W. Baker and C. A. Cornell, Vector-valued ground motion intensity measures for probabilistic seismic demand analysis, Tech. Rep. 150, vol. 321, Blume Earthquake Engineering Center, Stanford University, Stanford, CA, USA, 2005, http://blume.stanford.edu/Blume/TRList.html.

[27] F. Jalayer, "Direct probabilistic seismic analysis: implementing non-linear dynamic assessments," Ph.D. thesis, Department of Civil and Environmental Engineering, Stanford University, vol. 244, Stanford, CA, USA, 2003, http://www.stanford.edu/group/rms/.

[28] J. Neter, M. H. Kutner, C. J. Nachtsheim, and W. Wasserman, Applied Linear Statistical Models, McGraw-Hill, Boston, MA, USA, 4th edition, 1996.

[29] N. Luco, L. Manuel, S. Baldava, and P. Bazzurro, "Correlation of damage of steel moment-resisting frames to a vector-valued set of ground motion parameters," in Proceedings of the Ninth International Conference on Structural Safety and Reliability, vol. 8, Rome, Italy, 2005.

[30] P. Bazzurro, Probabilistic Seismic Demand Analysis, Vol. 329, Department of Civil and Environmental Engineering, Stanford University, Stanford, CA, USA, 1998, http://www. stanford.edu/group/rms/.

[31] P. P. Cordova, G. G. Deierlein, S. S. Mehanny, and C. A. Cornell, "Development of a two-parameter seismic intensity measure and probabilistic assessment procedure," in In The Second US-Japan Workshop on Performance-Based Earthquake Engineering Methodology for Reinforced Concrete Building Structures, Sapporo, Japan, pp. 187-206, 2000.

[32] D. Vamvatsikos, "Seismic performance, capacity and reliability of structures as seen through incremental dynamic analysis," Ph.D. dissertation, Stanford University, Stanford, CA, USA, 2002.
[33] N. Luco and C. A. Cornell, "Structure-specific scalar intensity measures for near-source and ordinary earthquake ground motions," Earthquake Spectra, vol. 23, no. 2, pp. 357-392, 2007.

[34] D. Vamvatsikos and C. A. Cornell, "Developing efficient scalar and vector intensity measures for IDA capacity estimation by incorporating elastic spectral shape information," Earthquake Engineering \& Structural Dynamics, vol. 34, no. 13, pp. 1573-1600, 2005.

[35] C. A. Cornell, F. Jalayer, R. O. Hamburger, and D. A. Foutch, "Probabilistic basis for 2000 SAC federal emergency management agency steel moment frame guidelines," Journal of Structural Engineering, vol. 128, no. 4, pp. 526-533, 2002.

[36] FEMA 350, Recommended Seismic Design Criteria for New Steel Moment-Frame Buildings, SAC Joint Venture, Federal Emergency Management Agency, Washington, DC, USA, 2000.

[37] FEMA 351, Recommended Seismic Evaluation and Upgrade Criteria for Existing Welded Steel Moment-Frame Buildings, SAC Joint Venture, Federal Emergency Management Agency, Washington, DC, USA, 2000.

[38] H. Aslani, "Probabilistic earthquake loss estimation and loss deaggregation in buildings," Ph.D. thesis, Department of Civil and Environmental Engineering, Stanford University, Stanford, CA, USA, 2005.

[39] M. Alembagheri, "Earthquake damage estimation of concrete gravity dams using linear analysis and empirical failure criteria," Soil Dynamics and Structural Dynamics, vol. 90, pp. 327-339, 2016.

[40] R. L. Hall, S. C. Woodson, and J. M. Nau, Seismic Stability Evaluation of Folsom Dam and Reservoir Project, Report 3. Concrete Gravity Dam. No. WES/TR/GL-87-14-3, Army Engineer Waterways Experiment Station Vicksburg Ms Geotechnical Lab, 1989.

[41] V. Valamanesh, H. E. Estekanchi, A. Vafai, and M. Ghaemian, "Application of the endurance time method in seismic analysis of concrete gravity dams," Scientia Iranica, vol. 18, no. 3, pp. 326-337, 2011.

[42] Y. Yazdani and M. Alembagheri, "Nonlinear seismic response of a gravity dam under near-fault ground motions and equivalent pulses," Soil Dynamics and Earthquake Engineering, vol. 92, pp. 621-632, 2017.

[43] M. Alembagheri, "Dynamics of submerged intake towers including interaction with dam and foundation," Soil Dynamics and Earthquake Engineering, vol. 84, pp. 108-119, 2016.

[44] J. Lee and G. L. Fenves, "A plastic-damage concrete model for earthquake analysis of dams," Earthquake Engineering \& Structural Dynamics, vol. 27, no. 9, pp. 937-956, 1998.

[45] PEER, PEER Strong Motion Database, 2016, http://ngawest2. berkeley.edu/.

[46] FEMA 450, NEHRP Recommended Provisions for Seismic Regulations for New Buildings and Other Structures, Federal Emergency Management Agency, Washington, DC, USA, 2003.

[47] P. G. Somerville and H. K. Thio, "Probabilistic vector-valued ground motion intensity measures and engineering demand measures for the PEER Van Nuys Holiday Inn PBEE testbed," SCEC 2003 Project Report, 2003. 


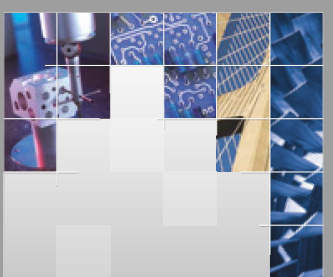

\section{Enfincering}
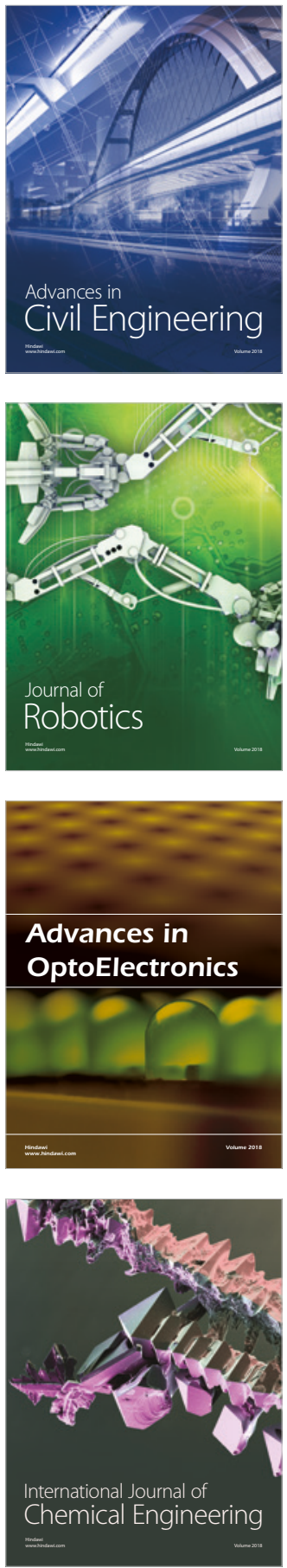

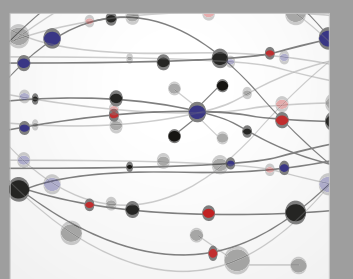

\section{Rotating \\ Machinery}

The Scientific World Journal

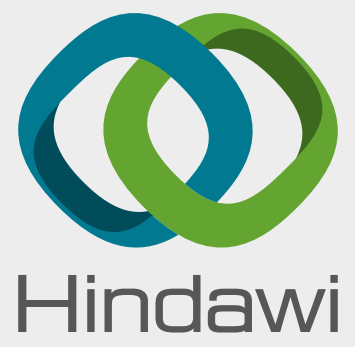

Submit your manuscripts at

www.hindawi.com
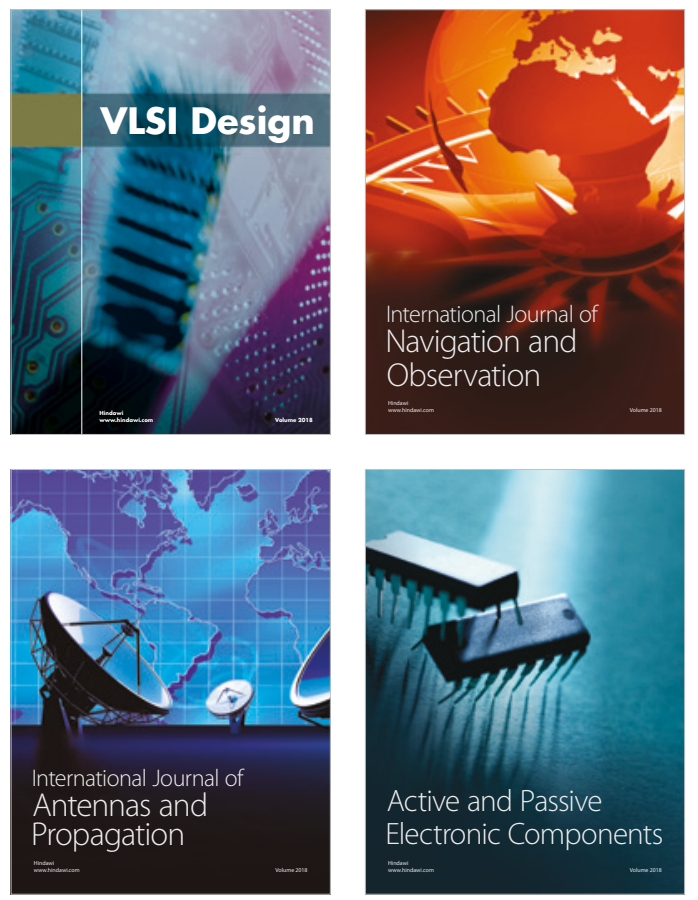
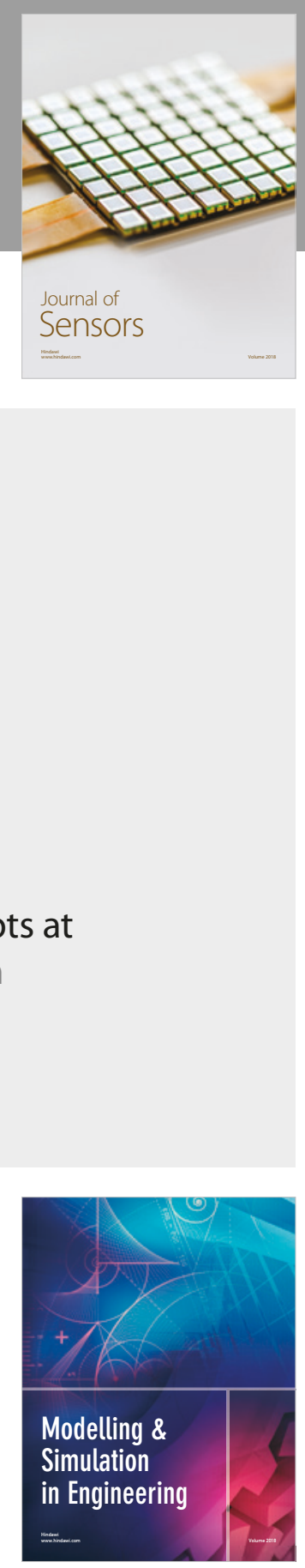

\section{Advances \\ Multimedia}
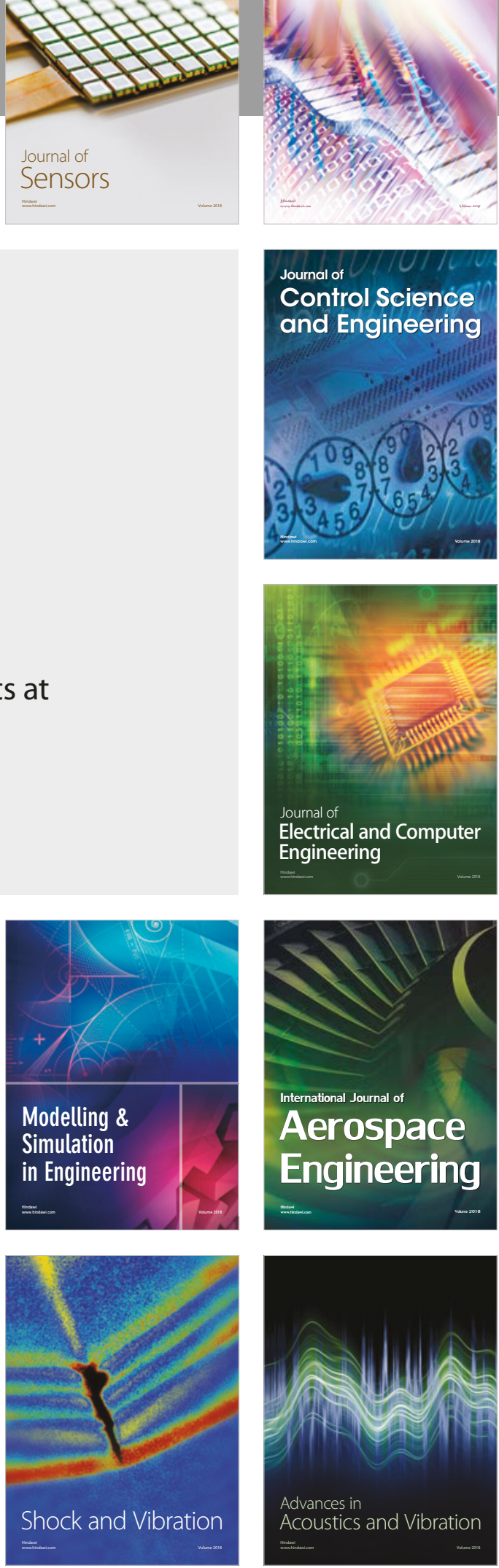